Pesq. Vet. Bras. 38(1):23-28, janeiro 2018 DOI: $10.1590 / \mathrm{S} 0100-736 \mathrm{X} 2018000100004$

\title{
Perfil da implantação de cisticercos de Taenia saginata em sítios musculares não usuais e sua importância para a Saúde Pública ${ }^{1}$
}

\author{
Rafaella Paola M. Guimarães Peixoto ${ }^{2}$, Paulo Sérgio A. Pinto ${ }^{2 *}$, Tatiane O. Santos ${ }^{3}$, \\ Letícia F. Silva ${ }^{2}$, Emílio C. Acevedo-Nieto ${ }^{2}$ e André Ricardo Silva ${ }^{2}$
}

\begin{abstract}
Guimarães Peixoto R.P.M., Pinto P.S.A., Santos T.O., Silva L.F., Acevedo-Nieto E.C. \& Silva A.R. 2018. [Profile of Taenia saginata cysticerci implantation in unusual sites and its importance for public health.] Perfil da implantação de cisticercos de Taenia saginata em sítios musculares não usuais e sua importância para a Saúde Pública. Pesquisa Veterinária Brasileira 38(1):23-28. Departamento de Veterinária, Laboratório de Inspeção de Produtos de Origem Animal, Universidade Federal de Viçosa, Campus Universitário, Av. PH Rolfs s/n, Viçosa, MG 36570-000, Brazil. E-mail: pintopsa@ufv.br

Cysticercosis is a worldwide zoonosis, which demands proper control and monitoring during all beef production chain. In Brazil, the key point for controlling this zoonosis is the anatomopathological exam conducted in slaughterhouses during the post-morten inspection. This study aimed to describe the cysticerci location in tissues not usually examined during the inspection, and to check their viability in bovines infected with Taenia saginata eggs (group 1: experimental; group 2: natural). After slaughtering, animal from both groups were routinely examined for cysticercosis, according official Brazilian standards; group 1 animals were also examined in additional anatomic regions: end cuts (chuck, rump, strip loin, and shoulder), liver, esophagus, diaphragm and pillars. In group 1, cysticerci were identified in chuck (8.2\%), shoulder (6.6\%), strip loin (6.2\%), and rump (5.8\%), and also in tissues that are not usually considered during routine inspection, such as diaphragm (2.7\%), liver $(12.0 \%)$ and esophagus $(1.2 \%)$. Still in group 1 , the routine inspection identified cysticerci in hearth $(37.7 \%)$, head muscles $(17.1 \%)$, and tongue $(2.3 \%)$. In group 2, cysticerci were identified in hearth $(61.8 \%)$, head muscles (38.2\%), and liver (10.2\%). The viability of cysticerci were predominant in rump $(80.0 \%)$, diaphragm $(71.4 \%)$ and esophagus $(66.7 \%)$ in animals from group 1 , while non-viable cysticerci were more frequent in head muscles $(77.3 \%)$, hearth $(76.3 \%)$, liver $(71.0 \%)$, and tongue $(50.0 \%)$. In group 2, head muscles presented $68.3 \%$ of the viable cysticerci, while non-viable cysticerci were identified in liver (87.5\%), tongue (66.7\%), and hearth (63.2\%). The high frequencies of viable cysticerci in end cuts available for consumers, including natural infected bovines, is a Public Health concern, once in Brazil these products were usually consumed without proper heat treatment, increasing the risks of T. sagina$t a$ infection. The obtained results demonstrated the anatomopathological distribution of cysticercosis in different tissues in experimental and natural infected bovines, considering tissues that are routinely and not routinely examined during inspection. Then, the inspection procedures could be improved by adding such analysis in its routine procedures, in order to increase the proper control of the taeniasis-cysiticercosis complex and to decrease the Public Health risks.
\end{abstract}

INDEX TERMS: Bovine cysticercosis, prevention, routine inspection, Taenia saginata, parasitoses.

\footnotetext{
${ }^{1}$ Recebido em 24 de julho de 2015.

Aceito para publicação em 23 de março de 2017.

${ }^{2}$ Departamento de Veterinária, Laboratório de Inspeção de Produtos de Origem Animal, Universidade Federal de Viçosa, Campus Universitário, Avenida PH Rolfs s/n, Viçosa, MG 36570-000, Brasil. E-mails: rafaella.peixoto@
}

ufv.br, leticiaafs@gmail.com, ecanieto@gmail.com, andrericardovetevicosa@hotmail.com; *Autor para correspondência: pintopsa@ufv.br

${ }^{3}$ Departamento de Veterinária, Faculdade Anísio Teixeira, Rua Juracy Magalhães 222, Ponto Central, Feira de Santana, BA 44032-620, Brasil. E-mail: tatyvetoli@hotmail.com 
RESUMO.- A cisticercose bovina é uma zoonose de distribuição mundial. No Brasil, o controle é realizado através do diagnóstico anatomopatológico durante a inspeção post-mortem nos matadouros. Objetivou-se neste estudo determinar a localização de cisticercos nos tecidos rotineiramente inspecionados e sobretudo nos tecidos não rotineiramente inspecionados, verificando a viabilidade dos cisticercos em bovinos infectados de forma experimental (grupo 1) e natural (grupo 2) com ovos de Taenia saginata. Em ambos os grupos foram analisados os tecidos rotineiramente inspecionados nas linhas de inspeção, de acordo com os padrões estabelecidos na legislação do Brasil. Adicionalmente, no grupo 1 foram selecionadas outras regiões anatômicas, representadas por quatro cortes comerciais (acém, alcatra, contrafilé, paleta), além do fígado, esôfago, diafragma e pilares. Com relação à frequência dos cisticercos no grupo 1 , nos cortes comerciais, foram encontrados $8,2 \%$ de cisticercos no acém, $6,6 \%$ na paleta, $6,2 \%$ no contrafilé e 5,8\% na alcatra. Outros tecidos não rotineiramente inspecionados para a exclusiva pesquisa por cisticercos que apresentaram lesões foram o diafragma, fígado e o esôfago, com $2,7 \%, 12,0 \%$ e $1,2 \%$ respectivamente. No grupo 1 , os sítios rotineiramente inspecionados predominantes foram o coração $(37,7 \%)$, músculos mastigatórios $(17,1 \%)$ e língua (2,3\%). No grupo 2 foram encontrados $61,8 \%$ dos cisticercos totais no coração, seguido dos músculos mastigatórios $(38,2 \%)$ e fígado $(10,2 \%)$. Com relação à viabilidade dos cisticercos no grupo 1 , os viáveis predominaram na alcatra $(80,0 \%)$, diafragma $(71,4 \%)$ e esôfago $(66,7 \%)$, já os cisticercos inviáveis predominaram nos músculos mastigatórios $(77,3 \%)$, coração $(76,3 \%)$, fígado $(71,0 \%)$ e língua (50\%). No grupo 2, o fígado apresentou $87,5 \%$ de cisticercos inviáveis, seguidos da língua $(66,7 \%)$ e coração $(63,2 \%)$, e nos tecidos mastigatórios foram encontrados $68,3 \%$ de cisticercos viáveis $(68,3 \%)$. 0 alto percentual de cisticercos viáveis encontrado nos cortes comerciais, inclusive nos bovinos naturalmente infectados, representa um alerta para a Saúde Pública, pois, no Brasil, são frequentemente consumidos sem sofrer o devido tratamento térmico para inativação do cisticerco, aumentando consideravelmente a chance de infecção por teniose. Os resultados revelaram amplo perfil da manifestação anatomopatológica da cisticercose em diferentes tecidos de bovinos experimentalmente e naturalmente infectados, considerando-se tecidos musculares rotineiramente inspecionados ou não. Assim, o aprimoramento da inspeção sanitária das carcaças bovinas pode incrementar o controle do complexo teniose-cisticercose, diminuindo os riscos para a saúde pública.

TERMOS DE INDEXAÇÃO: Cisticercose bovina, prevenção, inspeção rotineira, cisticerco, Taenia saginata, saúde pública, parasitoses.

\section{INTRODUÇÃO}

A pecuária bovina é um dos setores mais importantes do agronegócio brasileiro e consequentemente da economia nacional (Brasil 2014). O Brasil possui o maior rebanho bovino comercial do mundo e é o maior exportador de carnes (USDA 2014). A produção mundial de carne bovina tem sido estimada em 68.0 milhões de toneladas e seu consumo per capita mundial é de 42.9 , e em países em desenvol- vimento, como no caso o Brasil, estima-se um consumo per capita de 33.7 (FAO 2014). Nesse contexto, destaca-se a importância da cisticercose bovina, cuja prevalência no país tem oscilado em torno de 1,05\% a 5\% (Santos 1993, Dutra et al. 2012), sinalizando riscos sanitários ao consumo de carnes que contenham cisticercos e futura manutenção do ciclo parasitário.

A cisticercose bovina é uma doença de caráter zoonótico e distribuição mundial. 0 agente etiológico em sua forma adulta é Taenia saginata, que acomete o ser humano como hospedeiro definitivo e, em sua forma larvar está presente na musculatura de bovinos, seu hospedeiro intermediário, caracterizando a cisticercose. Atualmente, é um dos grandes problemas para a saúde pública e também para pecuaristas, pois é a doença mais frequentemente diagnosticada em matadouros, acarretando prejuízos de ordem sanitária e econômica. Guimarães-Peixoto et al. (2012) estimaram prejuízos advindos da condenação por cisticercose bovina em torno de 120 milhões de reais, analisando o período de 2004 a 2008, no Estado do Paraná.

Usualmente o controle da cisticercose é realizado por meio de diagnóstico anatomopatológico durante a inspeção post-mortem realizada nos matadouros sob inspeção. Este procedimento consiste basicamente na observação macroscópica de regiões anatômicas consideradas de predileção para a implantação dos cisticercos, tais como músculos masséteres, pterigóideos externos e internos, língua, coração e diafragma.

As carcaças monocisticercósicas e aquelas parasitadas em sítios não convencionais podem passar despercebidas durante a inspeção de rotina, dificultando o seu correto destino, o que foi reforçado por um modelo probabilístico desenvolvido por Kyvsgaard et al. (1991), mostrando que mais de 85\% dos animais infectados podem passar despercebidos durante a inspeção de rotina. Contudo, apesar das limitações, a inspeção post-mortem ainda continua sendo um método importante, prático e específico para identificação dessa infecção (Souza et al. 2007a).

Objetivou-se avaliar a ocorrência de cisticercos em bovinos experimentalmente e naturalmente infectados com ovos de Taenia saginata, entre os tecidos rotineiramente inspecionados ou não, bem como verificar a viabilidade dos cisticercos, como subsídios ao diagnóstico anatomopatológico dessa doença.

\section{MATERIAL E MÉTODOS}

Um paciente positivo para teniose foi identificado na região de Tumiritinga, Minas Gerais, Brasil (latitude $18^{\circ} 58^{\prime} 45^{\prime \prime} \mathrm{S}$, longitude $41^{\circ} 38^{\prime} 43^{\prime \prime} \mathrm{W}$ ), por meio de exame coproparasitológico, sendo tratado com anti-helmíntico Niclosamida 1000mg (Atenase, UCI Farma $^{\circledR}$ ), de acordo com especificações do fabricante. A espécie Taenia saginata foi confirmada pela morfologia apresentada na microscopia direta, baseada nas ramificações uterinas das proglotes grávidas. 0 exemplar de tênia ficou armazenado sob refrigeração $\left(4^{\circ} \mathrm{C}\right)$, imersa em solução contendo água destilada e cloridrato de oxitetraciclina $500 \mathrm{mg}$ (Terramicina, Pfizer $^{\circledR}$ ). 0 preparo do inóculo consistiu da lavagem exaustiva do parasito em água destilada, dissecação do útero com auxílio de lupa e separação dos ovos após centrifugação a $2000 \mathrm{rpm} / 2$ minutos, seguidos de duas lavagens. Foi realizada a verificação da morfologia e observada a inte- 
gridade dos ovos da amostra com auxílio de microscópio óptico, procedendo-se em seguida a contagem dos mesmos e realizada a distribuição em alíquotas. Para a realização da inoculação experimental utilizou-se $1 \mathrm{ml}$ do inóculo contendo aproximadamente 120.000 ovos de Taenia saginata, administrado por via oral com auxílio de sonda gástrica diluído em $500 \mathrm{ml}$ de água, garantindo que toda a alíquota fosse ingerida pelo animal. Todos os procedimentos foram aprovados pelos Comitês de Ética da Universidade Federal de Viçosa para utilização de animais e seres humanos em pesquisa, conforme os Processos CEUA/UFV no 20/2011 e CEP/ UFV n $^{\circ} 12 / 2013$.

Em relação à amostragem da pesquisa, o grupo 1 constituiu-se de 9 bovinos machos, de raça mestiça holandês-zebu, com idade aproximada de seis meses, que foram infectados experimentalmente, conforme protocolo descrito anteriormente. Após o período de 150 dias foi realizado o abate do primeiro animal, e os demais em intervalos posteriores de 30 dias. A seleção dos animais enviados para o abate foi aleatória utilizando o programa Epiinfo 3.5.1 (CDC 2008). 0 grupo 2 foi constituído de dados provenientes de 157 bovinos naturalmente infectados, abatidos e inspecionados pelo Serviço de Inspeção Federal em um matadouro-frigorífico comercial, localizado no município de Colatina-ES (latitude $19^{\circ} 32^{\prime} 22^{\prime \prime} \mathrm{S}$ e longitude $40^{\circ} 37^{\prime} 50^{\prime \prime} \mathrm{W}$ ). Os bovinos desse grupo tinham idade predominante entre 36 e 48 meses.

0 exame post-mortem dos bovinos com infecção experimental e natural e o critério de diferenciação dos tipos de tecidos (rotineiramente inspecionados ou não) acompanharam as recomendações da legislação brasileira (Brasil 1971). Os animais do grupo 1 foram submetidos à análise dos tecidos rotineiramente inspecionados nas linhas de inspeção por um médico veterinário (coração, língua, músculos mastigatórios) e de outros tecidos inspecionados apenas no Departamento de Inspeção Final, quando são detectados cisticercos nos tecidos anteriores, por ocasião do exame prévio nas linhas de inspeção; esses últimos tecidos foram representados nessa pesquisa por quatro cortes comerciais, localizados nos quartos dianteiro (acém e paleta) e traseiro da carcaça, (alcatra e contrafilé),além do diafragma e seus pilares, do esôfago e do fígado,. A pesquisa desenvolvida com o grupo $1(\mathrm{n}=9)$ ), incluiu a análise dos seguintes parâmetros relativos ao desenvolvimento da cisticercose: localização anatômica, viabilidade e a intensidade de infecção. Dos animais do grupo $2(n=157)$, foram analisados somente os tecidos rotineiramente inspecionados, através de cortes padronizados realizados nas linhas de inspeção pelos agentes sanitários responsáveis no matadouro. 0 grupo 2 foi amostrado para avaliar a localização anatômica dos cisticercos e sua viabilidade. A identificação dos cisticercos foi realizada através de visualização macroscópica dos mesmos por uma equipe previamente treinada. Os cisticercos foram considerados viáveis quando continham fluído em seu interior e se apresentavam translúcidos com escoléx invaginado; aqueles em estado de mineralização ou caseosos foram classificados como inviáveis.

As análises da implantação dos cisticercos por região anatômica e da sua viabilidade foram realizadas pelo teste do Qui-quadrado $(\mathrm{p}<0,05)$ após correção de Yates.

\section{RESULTADOS}

Os sítios rotineiramente inspecionados nos bovinos infectados experimentalmente (grupo 1) evidenciaram as seguintes frequências de cisticercos: coração com 37,7\% dos cisticercos totais, músculos mastigatórios com 17,1\% e língua com 2,3\%. Houve uma grande diferença no grau de parasitismo do coração, mostrando animais sem infecção $(n=1)$, com infecção leve, 1 a 2 cisticercos $(n=2)$, alta, 9 a 15 cisticercos $(n=5)$, e intensa, 36 cisticercos $(n=1)$. Não se
Quadro 1. Presença e ausência de cisticercose nos animais experimentalmente (grupo $1, n=9$ ) e naturalmente infectados (grupo 2, n=157), de acordo com a região anatômica

\begin{tabular}{|c|c|c|c|c|c|c|c|c|c|}
\hline \multirow{3}{*}{$\begin{array}{c}\text { Região } \\
\text { anatômica }\end{array}$} & \multicolumn{4}{|c|}{ Grupo 1} & \multirow{3}{*}{$\begin{array}{c}\text { Região } \\
\text { anatômica }\end{array}$} & \multicolumn{4}{|c|}{ Grupo 2} \\
\hline & \multicolumn{2}{|c|}{ Presença } & \multicolumn{2}{|c|}{ Ausência } & & \multicolumn{2}{|c|}{ Presença } & \multicolumn{2}{|c|}{ Ausência } \\
\hline & $\mathrm{n}$ & $\%$ & $\mathrm{n}$ & $\%$ & & $\mathrm{n}$ & $\%$ & $\mathrm{n}$ & $\%$ \\
\hline \multicolumn{10}{|c|}{ Rotineiramente inspecionados } \\
\hline Mastigatórios $^{\mathrm{a}}$ & 06 & 66,7 & 03 & 33,3 & Mastigatórios $^{\mathrm{a}}$ & 55 & 35,0 & 102 & 65,0 \\
\hline Coração ${ }^{\mathrm{a}}$ & 08 & 88,9 & 01 & 11,1 & Coração ${ }^{b}$ & 90 & 57,3 & 67 & 42,7 \\
\hline Língua $^{\mathrm{a}}$ & 05 & 55,6 & 04 & 44,4 & Língua $^{c}$ & 03 & 1,9 & 154 & 98,1 \\
\hline \multicolumn{10}{|c|}{ Não rotineiramente inspecionados } \\
\hline Diafragma $^{a}$ & 02 & 22,2 & 07 & 77,8 & - & & & & \\
\hline Esôfago $^{a}$ & 01 & 11,1 & 08 & 88,9 & - & & & & \\
\hline Fígado $^{\mathrm{a}}$ & 05 & 55,6 & 04 & 44,4 & Fígado $^{\mathrm{d}}$ & 16 & 10,2 & 141 & 89,8 \\
\hline Contra file ${ }^{a}$ & 05 & 55,6 & 04 & 44,4 & - & & & & \\
\hline Alcatra $^{a}$ & 04 & 44,4 & 05 & 55,6 & - & & & & \\
\hline Acém $^{a}$ & 04 & 44,4 & 05 & 55,6 & - & & & & \\
\hline Paleta $^{a}$ & 05 & 55,6 & 04 & 44,4 & - & & & & \\
\hline
\end{tabular}

Letras sobrescritas diferentes na mesma coluna representam diferença estatística $(\mathrm{p}<0,05)$ ao teste do qui-quadrado.

observou diferença estatisticamente significante $(p>0,05)$ ao comparar as regiões anatômicas de maior ocorrência de cisticercose nos animais experimentalmente infectados, sendo rotineiramente inspecionadas ou não (Quadro 1). Os tecidos musculares dos bovinos infectados experimentalmente, que não são rotineiramente inspecionados, apresentaram 26,7\% dos cisticercos totais encontrados, sendo distribuídos nos valores de 8,2\% no acém, 6,6\% na paleta, $6,2 \%$ no contrafilé e $5,8 \%$ na alcatra. Os outros tecidos não rotineiramente inspecionados para a exclusiva pesquisa de cisticercos, que apresentaram as respectivas lesões foram o fígado com $12 \%$, o diafragma com $2,7 \%$ e o esôfago com $1,2 \%$ dos cisticercos totais.

Nos bovinos infectados naturalmente (grupo 2), foram analisados somente os sítios rotineiramente inspecionados por se tratarem de animais abatidos em matadouro comercial. A frequência de cisticercos nos sítios de predileção do grupo 2 foi a seguinte: coração $(61,8 \%)$, músculos mastigatórios (38,2\%), fígado $(10,2 \%)$ e língua (1,9\%). Houve diferença estatística quando comparados os sítios de predileção por animal naturalmente infectado $(\mathrm{p}<0,01)$. (Quadro 1).

Em relação à viabilidade dos cisticercos no grupo 1, houve predominância de cisticercos inviáveis nos músculos mastigatórios (77,3\%), seguidos do coração (76,3\%) e fígado $(71,0 \%)$. Os valores de cisticercos inviáveis observados nos tecidos não rotineiramente inspecionados, em ordem decrescente foram: contrafilé $(68,8 \%)$, paleta $(58,8 \%)$ e acém (52,4\%). Destaca-se que, os cisticercos viáveis predominaram na alcatra $(80,0 \%)$, diafragma $(71,4 \%)$ e esôfago $(66,7 \%)$ (Quadro 2). Quando comparada a ocorrência de cisticercos de acordo com a viabilidade nos tecidos rotineiramente inspecionados com os não rotineiramente inspecionados, observou-se diferença estatística significativa $(\mathrm{p}<0,01)$.

Em relação aos animais pertencentes ao grupo 2, pôde-se verificar que do total de cisticercos, 55,5\% apresentavam-se inviáveis e 44,5\% viáveis. A região anatômica rotineiramente inspecionada que apresentou maior número 
Quadro 2. Frequência (no) e percentual de viabilidade (\%) de cisticercos no grupo experimentalmente (grupo 1) e naturalmente infectados (grupo 2), de acordo com a região anatômica

\begin{tabular}{|c|c|c|c|c|c|}
\hline \multirow{3}{*}{$\begin{array}{c}\text { Região } \\
\text { anatômica }\end{array}$} & \multicolumn{2}{|c|}{ Grupo 1} & \multirow{3}{*}{$\begin{array}{c}\text { Região } \\
\text { anatômica }\end{array}$} & \multicolumn{2}{|c|}{ Grupo 2} \\
\hline & Presença & Ausência & & Presença & Ausência \\
\hline & $\%$ & $\%$ & & $\%$ & $\%$ \\
\hline
\end{tabular}

Rotineiramente inspecionados

\begin{tabular}{|c|c|c|c|c|c|c|c|c|c|}
\hline Mastigatórios $^{\mathrm{a}}$ & 10 & 22,7 & 34 & 77,3 & Mastigatórios ${ }^{\mathrm{b},}$ & 43 & 68,3 & 20 & 31,7 \\
\hline Coraçãa $0^{\mathrm{a}, \mathrm{b}}$ & 23 & 23,7 & 74 & 76,3 & Coração $0^{\mathrm{a,d}}$ & 35 & 36,8 & 60 & 63,2 \\
\hline Língua $^{\mathrm{a}, \mathrm{b}, \mathrm{c}, \mathrm{d}}$ & 03 & 50,0 & 03 & 50,0 & Língua $^{\mathrm{a}, \mathrm{c}, \mathrm{d}}$ & 01 & 33,3 & 02 & 66,7 \\
\hline Total & 36 & 24,5 & 111 & 75,5 & & 79 & 49 & 82 & 50,9 \\
\hline \multicolumn{10}{|c|}{ Não rotineiramente inspecionados } \\
\hline Diafragma $^{\mathrm{d}}$ & 05 & 71,4 & 02 & 28,6 & - & & & & \\
\hline sôfago a,b,c,d,e & 02 & 66,7 & 01 & 33,3 & - & & & & \\
\hline Fígado $0^{\mathrm{a}, \mathrm{b}, \mathrm{c}, \mathrm{e}, \mathrm{f}}$ & 09 & 29,0 & 22 & 71,0 & Fígado ${ }^{\mathrm{a}, \mathrm{c}, \mathrm{d}}$ & 02 & 12,5 & 14 & 87,5 \\
\hline Contra file ${ }^{\mathrm{a}, \mathrm{b}, \mathrm{c}, \mathrm{d}, \mathrm{e}, \mathrm{f}, \mathrm{s}}$ & 05 & 31,3 & 11 & 68,8 & - & & & & \\
\hline Alcatra ${ }^{c, d, e, h}$ & 12 & 80,0 & 03 & 20,0 & - & & & & \\
\hline Acém ${ }^{\mathrm{c}, \mathrm{d}, \mathrm{e}, \mathrm{f}, \mathrm{g} \mathrm{i}}$ & 10 & 47,6 & 11 & 52,4 & - & & & & \\
\hline Paleta, ${ }^{\text {ab, }, c, d, e, f, g, j, j}$ & 07 & 41,2 & 10 & 58,8 & - & & & & \\
\hline Total & 50 & 45,5 & 60 & 54,5 & & 02 & 12,5 & 14 & 87,5 \\
\hline Total geral & 86 & 33,5 & 171 & 66,5 & & 81 & 45,7 & 6 & \\
\hline
\end{tabular}

Letras sobrescritas diferentes na mesma coluna representam diferença estatística $(\mathrm{p}<0,05)$ ao teste do qui-quadrado.

de cisticercos inviáveis foi o coração, representando 63,2\%. Outro tecido que apresentou predominância de cisticercos inviáveis foi o fígado $(87,5 \%)$, destacando que este tecido não é rotineiramente inspecionado quanto à pesquisa da cisticercose. Na língua, a frequência de cisticercos inviáveis foi de $66,7 \%$, e, em contrapartida, nos tecidos mastigatórios foi encontrada maior frequência de cisticercos viáveis $(68,3 \%)$. Ao comparar o total de cisticercos viáveis nos tecidos rotineiramente inspecionados entre os grupos dos bovinos experimentalmente e naturalmente infectados, foi encontrada diferença estatística $(\mathrm{p}<0,01)$.

\section{DISCUSSÃO}

A presença de cisticercos em bovinos naturalmente ou experimentalmente infectados foi observada em tecidos rotineiramente inspecionados, bem como naqueles não rotineiramente inspecionados. 0 coração, por exemplo, apresentou cisticercos em mais da metade dos bovinos naturalmente infectados $(61,8 \%)$. Por outro lado, a viabilidade dos cisticercos foi baixa nesse tecido. Segundo Carvalho et al. (2006), o coração é um dos tecidos em que os cisticercos se calcificam mais rapidamente, tendência esta observada no presente estudo. Esta frequência e versatilidade de formas de manifestação da cisticercose reforçam a importância do coração como alvo diagnóstico em diferentes estádios de infecção, inclusive nos animais naturalmente infectados, que tendem a apresentar um baixo grau de infecção (Scandrett et al. 2009, Lopes et al. 2011). Destaca-se também a expressiva frequência encontrada nos músculos mastigatórios, tanto nos bovinos experimentalmente quanto os naturalmente infectados, revelando esses músculos também como sítios preferenciais para a implantação de cisticercos, concordando com outros relatos (Moreira et al. 2001, 2002, Souza et al. 2007b) e justificando a indicação do seu exame minucioso na inspeção de rotina. Souza et al. (2007b) encontraram $57,8 \%$ de parasitismo nos músculos da cabeça e 40,0\% do coração, invertendo a ordem de predominância, mas mantendo os dois tecidos como os mais frequentemente associados à implantação de cisticercos nos bovinos.

A língua foi o tecido rotineiramente inspecionado que apresentou o menor percentual de cisticercos, concordando com Moreira et al. (2002), que observaram a frequência de 2,2\%. Entretanto, Mello \& Carvalho (1981) encontraram um índice de $20,4 \%$ de cisticercos na língua, contrapondo aos resultados observados nesta pesquisa. Queiroz et al. (2008) associaram a baixa ocorrência de cisticercos na língua à dispensa da sua incisão nas linhas de inspeção, limitando-se somente à inspeção visual e palpação, salvo quando a carcaça é sequestrada para o Departamento de Inspeção Final, onde então sofre minuciosos cortes. Pondera-se que a maioria das pesquisas sobre o grau de parasitismo da cisticercose são realizadas com animais naturalmente infectados e abatidos sob a rotina de inspeção de carnes.

Analisando-se o perfil macroscópico da cisticercose em tecidos não rotineiramente inspecionados, destaca-se a presença de cisticercos no fígado, que representaram $12,0 \%$ nos animais do grupo 1 e $10,2 \%$ no grupo 2 , com uma predominância de formas inviáveis, atingindo $71,0 \%$ e $87,5 \%$, respectivamente. Uma grande variação do parasitismo no fígado vem sendo divulgada. Fukuda et al. (1998) relataram uma frequência na faixa de 0 a $75 \%$ e atribuíram a amplitude dessa diferença às variadas formas de diagnóstico; além disso, Costa et al. (2006) enfatizam que as lesões por cisticercos podem ser confundidas com as de outras doenças, sobretudo nos casos de cisticercos inviáveis (mineralizados ou não), reduzindo significativamente a especificidade do exame anatomopatológico como recurso diagnóstico. Almeida et al. (2006), relataram uma alta ocorrência de cisticercos no fígado (69,5\%), sendo em sua grande maioria inviáveis $(67,8 \%)$, entretanto, após teste histopatológico, só foram confirmadas $10,2 \%$ do total de lesões computadas para cisticercose, concordando com a frequência apresentada nesta pesquisa. A predominante inviabilidade dos cisticercos presentes no fígado bovino sinalizam para uma menor importância deste órgão como sítio de eleição para a inspeção rotineira da cisticercose em detrimento à outros tecidos musculares.

A presença de cisticercos nos animais experimentalmente infectados, onde foi possível avaliar tecidos não rotineiramente inspecionados, evidenciou-se frequências de $2,7 \%$ no diafragma e de $1,2 \%$ no esôfago, enfatizando a importância da inspeção do diafragma e seus pilares, que foi reforçado por Queiroz et al. (2008), ao propor a sua indicação como um novo parâmetro de exame para as linhas de inspeção.

Em relação aos músculos esqueléticos, a frequência e a distribuição dos cisticercos encontrados por corte comercial $(8,2 \%$ no acém, $6,6 \%$ na paleta, $6,2 \%$ no contra filé e $5,8 \%$ na alcatra) se mostraram, na maioria, próximas às apresentadas por outros autores como Soares et al. (2011) e Lopes et al. (2011). Ressalta-se que, na presente pesquisa a picanha já se integra à alcatra. Por serem de elevado valor comercial esses cortes não sofrem minuciosa inspeção rotineira nas linhas de inspeção, revelando poucos dados disponíveis na literatura, sobretudo quanto à viabilidade 


\section{Quadro 3. Cisticercos encontrados de acordo com a região anatômica e viabilidade nos animais infectados experimentalmente}

\begin{tabular}{lcccccc}
\hline \multicolumn{1}{c}{ Região anatômica } & \multicolumn{2}{c}{ Viáveis } & & \multicolumn{2}{c}{ Inviáveis } & Total \\
\cline { 2 - 3 } & $\mathrm{N}$ & $\%$ & & $\mathrm{~N}$ & $\%$ & \\
\hline Rotineiramente inspecionados & 36 & 24,5 & & 111 & 75,5 & 147 \\
Não rotineiramente inspecionados & 50 & 45,5 & & 60 & 54,5 & 110
\end{tabular}

Houve diferença ( $\mathrm{p}<0,01)$ estatística pelo teste do qui-quadrado. Correção de Yates realizada devido à dispersão com 1 grau de liberdade.

dos cisticercos de acordo com os grupos musculares, mas que se constituem em importantes vias de transmissão da teniose.

Quando se comparou a viabilidade dos cisticercos nos tecidos rotineiramente inspecionados com os não rotineiramente inspecionados nos bovinos experimentalmente infectados, foi encontrada diferença estatística significativa $(\mathrm{p}<0,01)$ através do teste do qui-quadrado (Quadro 3 ), mostrando que a probabilidade de se encontrar cisticercos viáveis em tecidos não rotineiramente inspecionados é maior do que em tecidos rotineiramente inspecionados, aumentando a importância do diagnóstico da doença nesses tecidos. No grupo de bovinos experimentalmente infectados, onde foi possível avaliar outros tecidos, os cisticercos viáveis predominaram na alcatra $(80,0 \%)$, diafragma $(71,4 \%)$ e esôfago $(66,7 \%)$, locais ainda não reportados em outros estudos com presença dominante de cisticercos viáveis. Vale ressaltar que, no corte da alcatra, incluíram-se todos os cortes dessa região, os comercialmente denominados picanha, maminha e miolo, que são classificados como cortes nobres no mercado nacional. Dessa forma, considerando o alto percentual de cisticercos viáveis observados nesse corte, fica evidente a importância desse achado, visto que, esse tipo de corte é amplamente consumido no Brasil, sinalizando uma alta probabilidade do mesmo ser consumido sem o devido tratamento térmico para a inativação do cisticerco (mal passado) e aumentando o risco do indivíduo contrair a teniose. Este risco talvez seja menor em outras porções musculares relatadas com alta frequência de cisticercos, tais como os músculos mastigatórios, que usualmente são consumidos após intenso tratamento térmico. Assim deve-se atentar para essa versatilização da apresentação anatomopatológica da cisticercose prevista na rotina de inspeção de carnes, com destaque para a perspectiva de ocorrerem manifestações mais discretas em infecções naturais, que dificultam o diagnóstico.

Além dos achados observados, em especial nos tecidos não rotineiramente inspecionados, ressalta-se que outras características da cisticercose identificadas nessa pesquisa devem ser consideradas nas normativas e procedimentos de inspeção post mortem ou outros fins diagnósticos.

Pôde-se constatar que $93,2 \%$ dos animais naturalmente infectados eram monocisticercósicos, ou seja, portadores de único cisticerco nos sítios rotineiramente inspecionados, sugerindo maior dificuldade no diagnóstico desta parasitose nas linhas de inspeção. Diversos autores também relatam uma significante presença de animais monocisticercósicos (Santos 1984, Santos 1993, Manhoso \& Prata 2004, Souza et al. 2007a). Dessa forma, ressalta-se que, a detecção da infecção monocisticercósica deve ser uma im- portante preocupação dos fiscais sanitários, pois a inspeção da carne é um instrumento indispensável no controle desta zoonose (Souza et al. 2007a).

Adicionalmente, predominaram as infecções mais discretas em condições naturais, em geral devido à ingestão de menor número de ovos e em diferentes momentos, variando dessa forma o grau e perfil de distribuição dos cisticercos nos tecidos do bovino. Desta forma, alternativas ou aprimoramentos diagnósticos vêm sendo sugeridos. Eichenberger et al. (2011) sugeriram a utilização de um teste auxiliar através de cortes adicionais na musculatura e Wanzala et al. (2003), recomendaram o aumento da área e o número de locais inspecionados.

Os resultados revelaram um amplo perfil de manifestação anatomopatológica da cisticercose em diferentes tecidos bovinos rotineiramente inspecionados ou não, em matadouros, concordando com achados científicos anteriormente relatados, mas também indicando novas evidências, sobretudo quanto à frequência e à viabilidade dos cisticercos encontrados nos diferentes tecidos. Os resultados reforçam a premissa de que as medidas de controle do complexo teniose-cisticercose bovina devem ser mantidas e ainda aprimoradas pelos Órgãos Fiscalizadores, devendo-se atentar para uma atualização na legislação vigente no que diz respeito aos tecidos de inspeção de rotina para a pesquisa de cisticercos e uma necessidade de conscientização da população para o consumo de carnes somente inspecionadas e com o devido tratamento térmico.

\section{CONCLUSÕES}

Os sítios musculares considerados rotineiros para a inspeção da cisticercose, tais como coração e músculos mastigatórios, se confirmaram como importantes tecidos para o diagnóstico da cisticercose bovina, tanto a relacionada à infecção natural como experimental. Entretanto, a probabilidade de se encontrar cisticercos viáveis foi maior em tecidos não rotineiramente inspecionados nos animais experimentalmente infectados, alertando para potencial risco para a Saúde Pública.

Ressalta-se que, a utilização isolada do exame macroscópico como método diagnóstico ainda apresenta deficiências, sobretudo em animais monocisticercósicos (condição mais frequente) ou naqueles com grau leve de infecção, onde os cisticercos podem passar despercebidos.

Esses achados servem de alerta para Saúde Pública e autoridades competentes, uma vez que indicam a necessidade de atualização da legislação, quanto aos critérios de inspeção da cisticercose bovina nas linhas de inspeção.

Agradecimentos.- Os autores agradecem à FAPEMIG, CNPq e CAPES pelo suporte financeiro.

\section{REFERÊNCIAS}

Almeida D.O., Igreja H.P., Alves F.M.X., Santos I.F. \& Tortelly R. 2006. Cisticercose bovina em matadouro-frigorífico sob inspeção sanitária no município de Teixeira de Freitas-BA: prevalência da enfermidade e análise anatomopatológica de diagnósticos sugestivos de cisticercose. Revta Bras. Ciênc. Vet. 13(3):178-182.

Brasil 1971. Inspeção de carnes: padronização de técnicas, instalações e equipamentos. Tomo I. Bovinos. DIPOA/DICAR, Ministério Agricultura Pecuária e Abastecimento (MAPA), Brasília, DF. 183p. 
Brasil 2014. Plano mais pecuária. Ministério da Agricultura Pecuária e Abastecimento (MAPA), Brasília, DF. 34p.

Carvalho L.T., Costa R.F.R., Santos I.F. \& Carvalho A.L.T. 2006. Prevalência de cisticercose em bovinos abatidos em matadouro frigorífico sob inspeção federal em Minas Gerais. Revta Bras. Ciênc. Vet. 13(2):109-112.

CDC 2008. Epi info 3.5.1. Center of Disease Control and Prevention (CDC). Disponível em <http://wwwn.cdc.gov/epiinfo/> Acessado em 10 jun. 2015.

Costa R.F.R., Santos I.F., Nascimento E.R. \& Tortelly R. 2006. Caracterização das reações inflamatórias em corações de bovinos comercializados na cidade de Nova Friburgo/RJ. Revta Bras. Ciênc. Vet. 13(2):76-79.

Dutra L.H., Girotto A., Vieira R.F.C., Vieira T.S.W.J., Zangirolamo A.F., Marques F.A.C., Headley S.A. \& Vidotto O. 2012. The prevalence and spatial epidemiology of cysticercosis in slaughtered cattle from Brazil. Semina, Ciênc. Agrárias 33(5):1887-1896.

Eichenberger R.M., Stephan R. \& Deplazes P. 2011. Increased sensitivity for the diagnosis of Taenia saginata cysticercus infection by additional heart examination compared to the EU-approved routine meat inspection. Food Control 22(6):989-992.

FAO 2014. Food Outlook: biannual report on global food markets. Food and Agriculture Organization of the United Nations. Disponível em <http://www.fao.org/3/a-i4136e.pdf>

Fukuda R.T., Santos I.F. \& Andrade C.R. 1998. Estudo comparativo entre técnicas de inspeçäo do diafragma para o diagnóstico da cisticercose bovina. Revta Hig. Alim. 12(55):51-62.

Guimarães-Peixoto R.P.M., Souza V.K., Pinto P.S.A. \& Santos T.O. 2012. Distribuição e identificação das regiões de risco para a cisticercose bovina no Estado do Paraná. Pesq. Vet. Bras. 32(10):975-979.

Kyvsgaard N.C., Ilsoe B., Henriksen S.A., Feld N.C. \& Nansen P. 1991. Evaluation of an enzyme-linked immunosorbent assay (ELISA) for detection of Taenia saginata cysticercosis in cattle. Acta Veterinariae 32(3):233241.

Lopes W.D.Z., Santos T.R., Soares V., Nunes J.L.N., Mendonça R.P., Lima R.C.A., Sakamoto C.A.M., Costa G.H.N., Soccol V.T., Oliveira G.P. \& Costa A.J. 2011. Preferential infection sites of Cysticercus bovis in cattle experimentally infected with Taenia saginata eggs. Res. Vet. Sci. 90:84-88.

Manhoso F.F.R. \& Prata L.F. 2004. Prevalência de cisticercose bovina na Região Oeste do estado de São Paulo. Revta Hig. Alim. 18:42-49.

Mello M.R. \& Carvalho J.B. 1981. Cisticercose em bovinos abatidos no ma- tadouro de Paracambi, Estado do Rio de Janeiro. Revta Bras. Med. Vet. 4(2):35-37.

Moreira M.D., Reis D.O., Almeida L.A. \& Santos W.L.M. 2001. Zoonoses reemergentes: a cisticercose bovina em matadouros de Uberlândia, MG. Higiene Alimentar. 15(85):16-19.

Moreira M.D., Almeida L.P., Reis D.O. \& Santos W.L.M. 2002. Cisticercose bovina: um estudo com bovinos abatidos em matadouro municipal de Uberlândia, MG. Higiene Alimentar 16(100):37-41.

Queiroz M.G., Ferreira J.M. \& Bandeira CM. 2008. Utilização do músculo diafragma e seus pilares como parâmetro na linha de inspeção da cisticercose bovina. Revta Bras. Ciênc. Vet. 15(3):152-158.

Santos I.F. 1984. Diagnóstico da cisticercose bovina em matadouros: novas técnicas de exame de esôfago e diafragma. Tese de Doutorado em Saúde Pública, Universidade de São Paulo, São Paulo, 127p.

Santos I.F. 1993. Diagnóstico da cisticercose bovina em matadouros: exame dos pilares diafragmáticos. Higiene Alimentar 7(25):26-34.

Scandrett B., Parker S., Forbes L., Gajadhar A., Dekumyoy P., Waikagul J. \& Haines D. 2009. Distribution of Taenia saginata cysticerci in tissues of experimentally infected cattle. Vet. Parasitol. 164(2-4):223-231.

Soares V.E., Belo M.A.A., Rezende P.C.B., Soccol V.T., Fukuda R.T., Oliveira G.P. \& Costa A.J. 2011. Distribution of Taenia saginata metacestodes: a comparison of routine meat inspection and carcase dissection results in experimentally infected calves. Annals Trop. Med. Parasitol. 105(5):393401.

Souza W.K., Pessôa-Silva M.C., Minozzo J.C. \& Thomaz-Soccol V. 2007a. Prevalência da cisticercose bovina no estado do Paraná, sul do Brasil: avaliação de 26.465 bovinos inspecionados no SIF 1710. Semina, Ciênc. Agrárias 28(4):675-684.

Souza W.K., Pessôa-Silva M.C., Kowalczuk M., Marty S. \& Thomaz-Soccol V. 2007b. Regiões anatômicas de maior ocorrência de Cysticercus bovis em bovinos submetidos à Inspeção Federal em matadouro-frigorífico no município de São José dos Pinhais, Paraná, de julho a dezembro de 2000. Revta Bras. Parasitol. Vet. 16(2):92-96.

USDA 2014. USDA Foreign Agricultural Service. United States Department of Agriculture. Disponível em <http://apps.fas.usda.gov/psdonline/> Acesso em jun. 2015.

Wanzala W., Onyango-Abuje J.A., Kang' ethe E.K., Zessin K.H., Kyule N.M., Baumann M.P.O., Ochaud H. \& Harrison L.J.S. 2003. Control of Taenia saginata by post-mortem examination of carcasses. African Hlth Sci. 3(2):68-76. 